\title{
Erratum to: A survey-based evaluation of community- based co-management of forest resources: a case study of Baishuijiang National Natural Reserve in China
}

\author{
Zhu Ting • Ganesh P. Shivakoti • Chen Haiyun • David Maddox
}

Published online: 15 January 2012

(C) Springer Science+Business Media B.V. 2012

\section{Erratum to: Environ Dev Sustain DOI 10.1007/s10668-011-9316-6}

In Fig. 4, the firewood amount of Yanggashan in 2006 should be 11,100. The firewood amount of Diebuzhai in 2006 should be 10,900, and the data of Diebuzhai in 2010 should be 11,118 (Unit: KG/year).

In Fig. 5, the firewood amount of non-participator in Caoheba should be 11,706. In Diebuzhai, the firewood amount of participator should be 12,106, and the data for nonparticipator should be 11,000 (Unit: KG/year).

In Fig. 6, the correct data of average income of non-timber forest products should be as follows: 38.21 in 2006 and 7.49 in 2010 for Caoheba; 127.38 in 2006 and 19.98 in 2010 for Yanggashan; 112.42 in 2006 and 17.49 in 2010 for Diebuzhai; and 18.32 in 2006 and 8.18 in 2010 for Liziba (Unit: US\$/Year).

In Fig. 8, the correct data of livestock amount between 2006 and 2010 should be as follows: 3.71 in 2006 and 5.58 in 2010 for Caoheba; 3.37 in 2006 and 5.81 in 2010 for

The online version of the original article can be found under doi:10.1007/s10668-011-9316-6.

Z. Ting · G. P. Shivakoti · C. Haiyun $(\bowtie)$

School of Environment, Resources and Development, Asian Institute of Technology,

P.O. Box 4, Klong Luang Pathumthani, Bangkok 12120, Thailand

e-mail: chenhy.zhut@yahoo.com.cn

Z. Ting

e-mail: chyzt311@yahoo.com.cn

G. P. Shivakoti

e-mail: ganesh@ait.ac.th

D. Maddox

Sound Science LLC, 415 E. 52nd St, 1DC, New York, NY, USA

e-mail: david@sound-science.org 


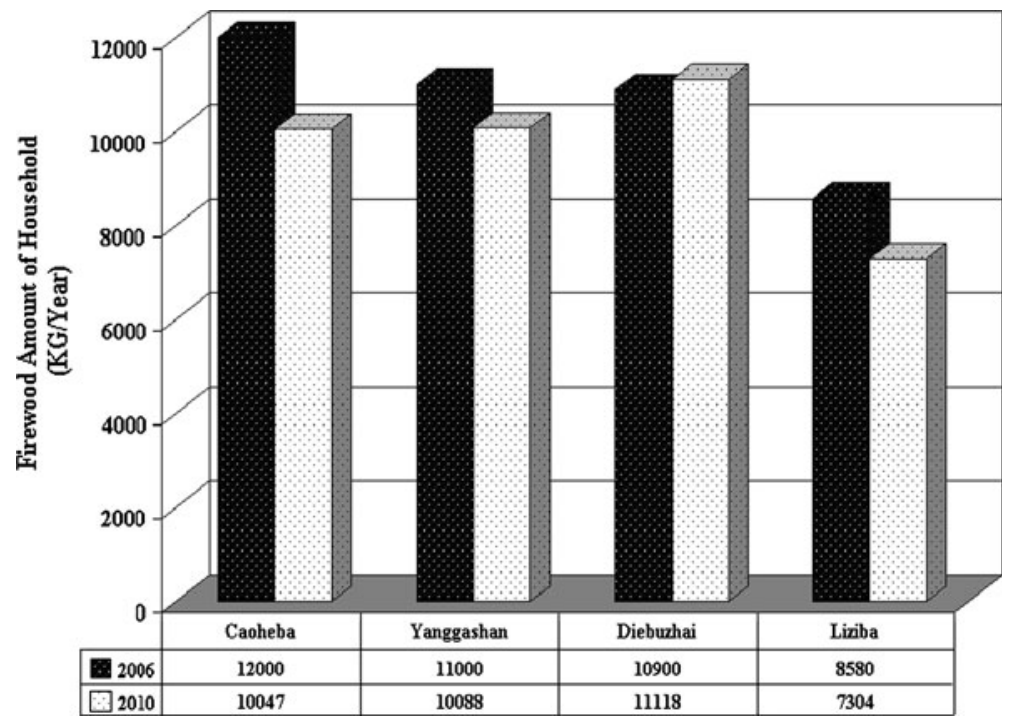

Fig. 4 Differences between 2006 and 2010 in firewood consumption in different communities

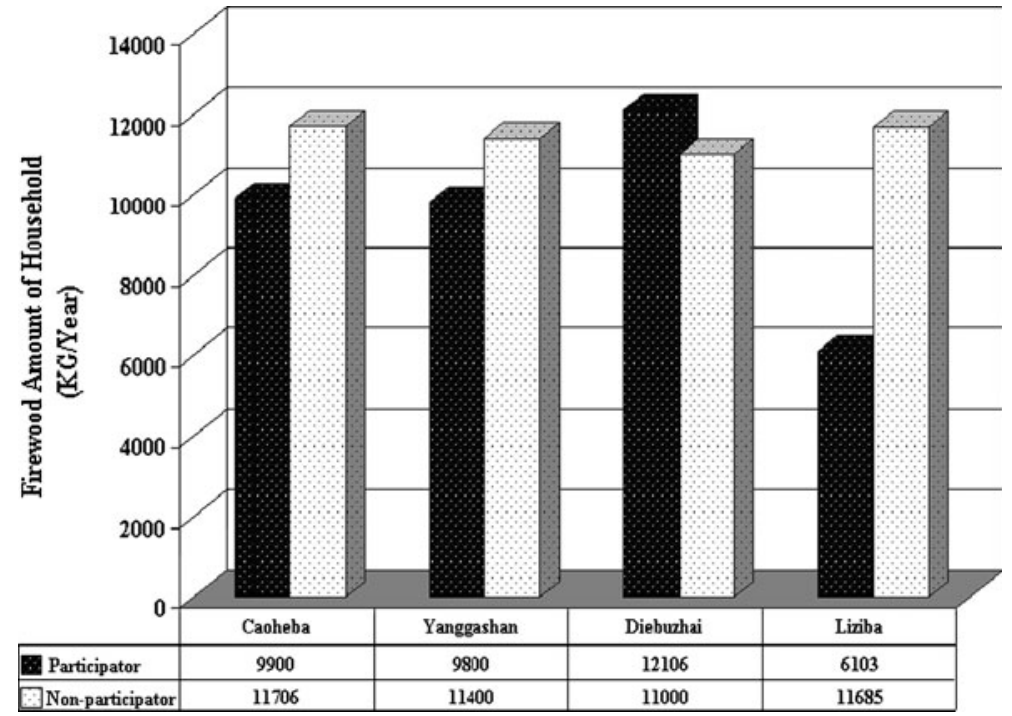

Fig. 5 Differences between CBCM participant households and non-participant households firewood consumption 


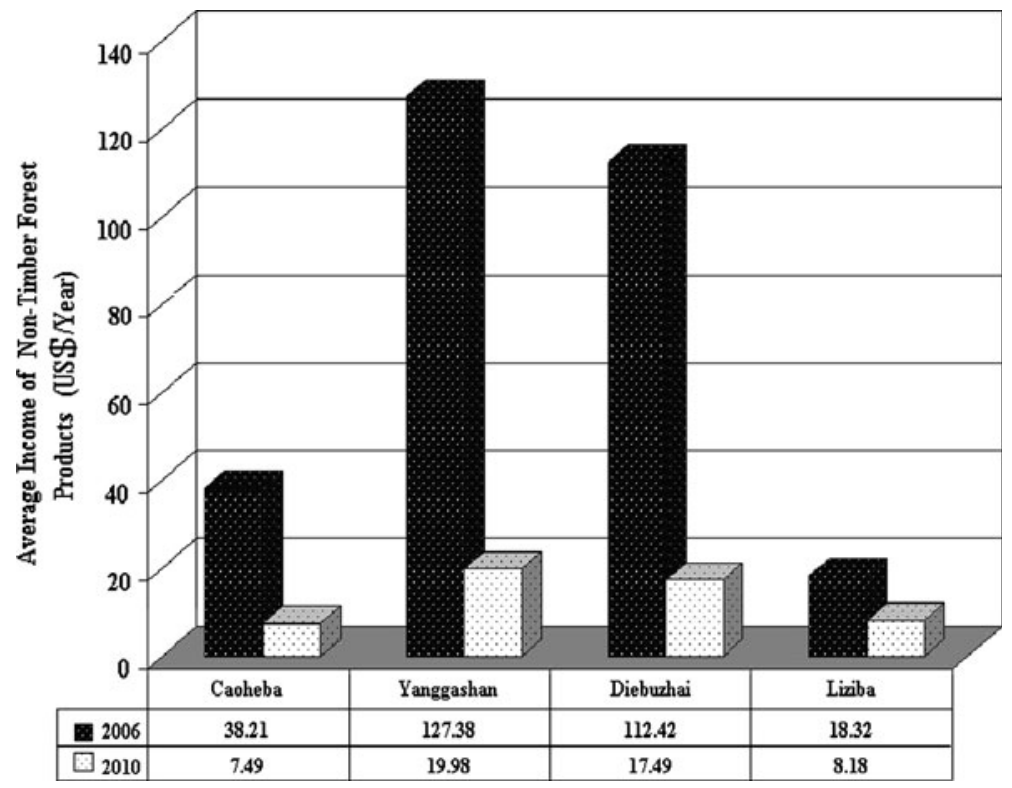

Fig. 6 Differences between 2006 and 2010 in non-timber forest product value

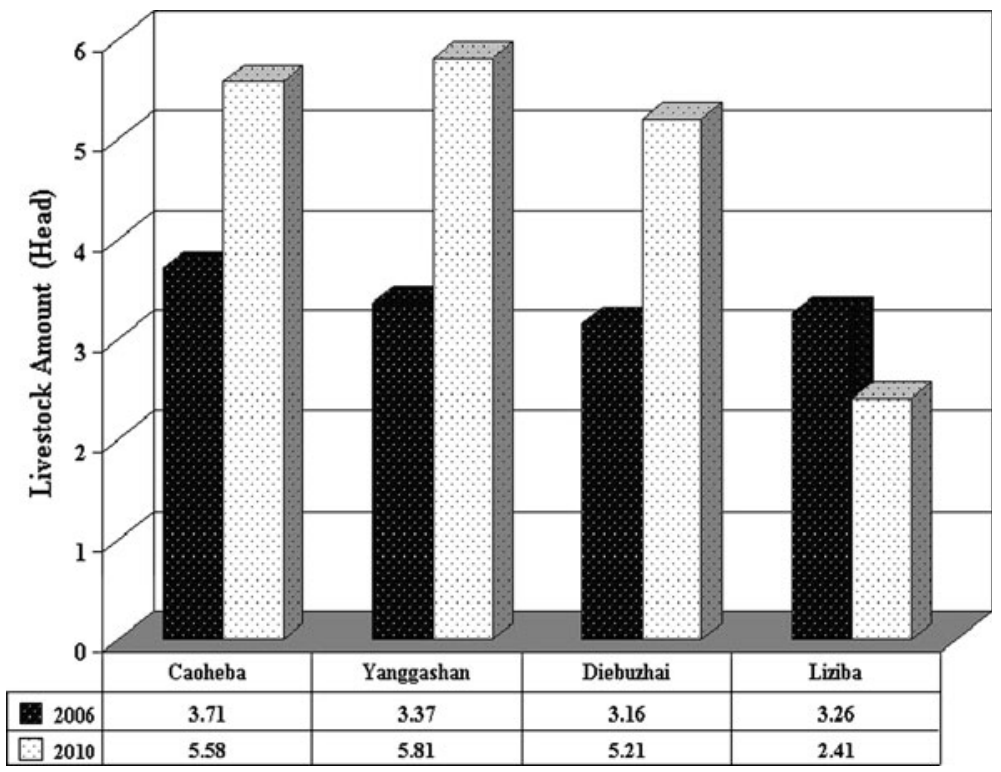

Fig. 8 Differences between 2006 and 2010 in the amount of livestock breeding 


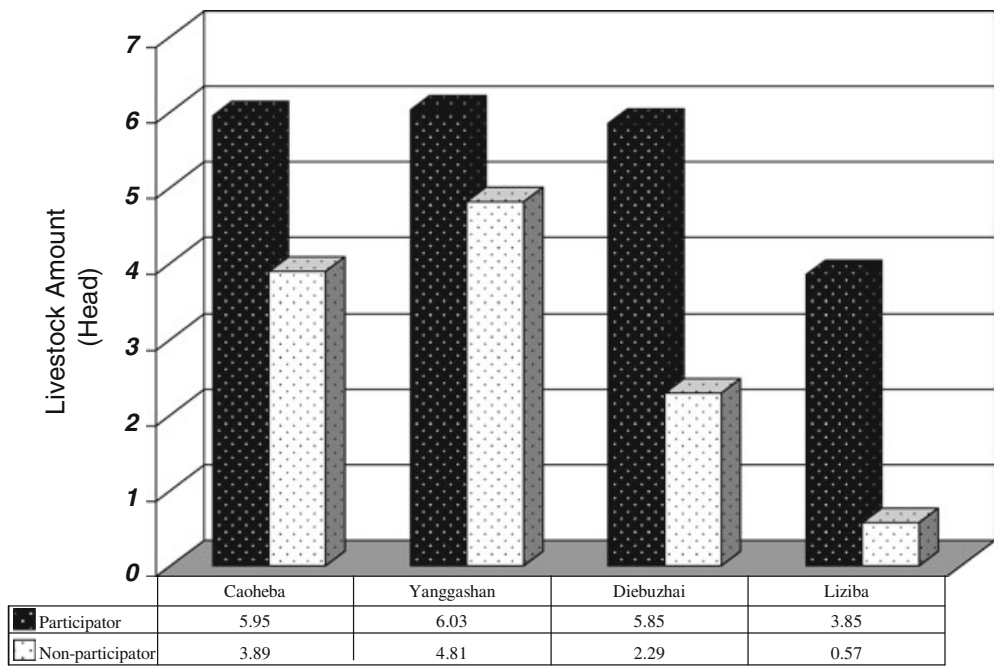

Fig. 9 Difference between CBCM participant households and non-participant households in livestock breeding

Yanggashan; 3.16 in 2006 and 5.21 in 2010 for Diebuzhai; and 3.26 in 2006 and 2.41 in 2010 for Liziba (Unit: Head).

In Fig. 9, the correct data of livestock amount between participator and non-participator in Liziba should be as follows: 3.85 for participator, 0.57 for non-participator (Unit: Head). 